\title{
Erratum to: Relationship between the Central Government and Local Governments of Contemporary China
}

\section{Erratum to:}

F. Zhou and M. Tan, Relationship between the Central

Government and Local Governments of Contemporary China, Social Development Experiences in China, https://doi.org/10.1007/978-981-10-4388-8

In the original version of the book, the co-publisher name "Science Press" has been changed as "China Social Sciences Press" in the Copyright page of Frontmatter. 